\section{A Full-radiator Lamp designed to replace the Tungsten Strip Lamp as a Pyrometric Standard}

TUNGSTEN strip lamps are used extensively as standard sources of luminance in photometry and in particular for the calibration of optical pyrometers. They have been shown to be stable within the limits of visual optical pyrometry ${ }^{1}$ provided they are well designed and certain precautions are taken with the operating conditions such as the ambient temperature, orientation of the plane of the filament with respect to the optic axis, direction of flow of the current, etc. However, when we try to oxploit the higher potential accuracy of photoelectric pyrometry it is soon found that the conventional tungsten strip lamp imposes severe limitations on the reproducibility of reading because of the aforementioned defects ${ }^{2}$. The use of the more sensitive photoelectric method also reveals variations in surface luminance previously undetected ${ }^{3}$. These variations become more intense as tho filament becomes thermally otched, and after prolonged use the crystal growth produces regions of varying reflectivity plainly visible when the filament is cold. At incandescence, however, the consequent variations in luminance are not detectable with the visual optical pyrometer. Scanning such a filament photoelectrically shows variation of the order of 2 per cent and it is also observed that thore are difforences in the polarization of the light emitted from different parts of the filament. These effects will be discussed in more detail in a paper to be published. In order to overcomo these difficulties and provide ourselves with a uniform disk of light independent of surface variations in the filament we aro proposing to use a full radiator to replace the tungsten strip in a lamp assembly.

A form of lamp which we have designed is shown in Fig. I; the full radiator is a tube of tantalum $2 \mathrm{~mm}$ in diameter and $45 \mathrm{~mm}$ in length mounted horizontally at the centre of a spherical glass bulb $150 \mathrm{~mm}$ in diameter, with quartz windows for sighting axially down the tube. The tube is formed from a strip of tantalum and is welded along a seam beneath the tube. At its centre is placed a bundle of very fine tungsten wire which has been cut off at right angles to the axis of the tube so that when viewed end-on a very 'black' surface is presented. A short distance from one end of the tube is placed a tantalum diaphragm having a $1-\mathrm{mm}$ aperture, and it is the radiation from this aperture which is expected to approxi-
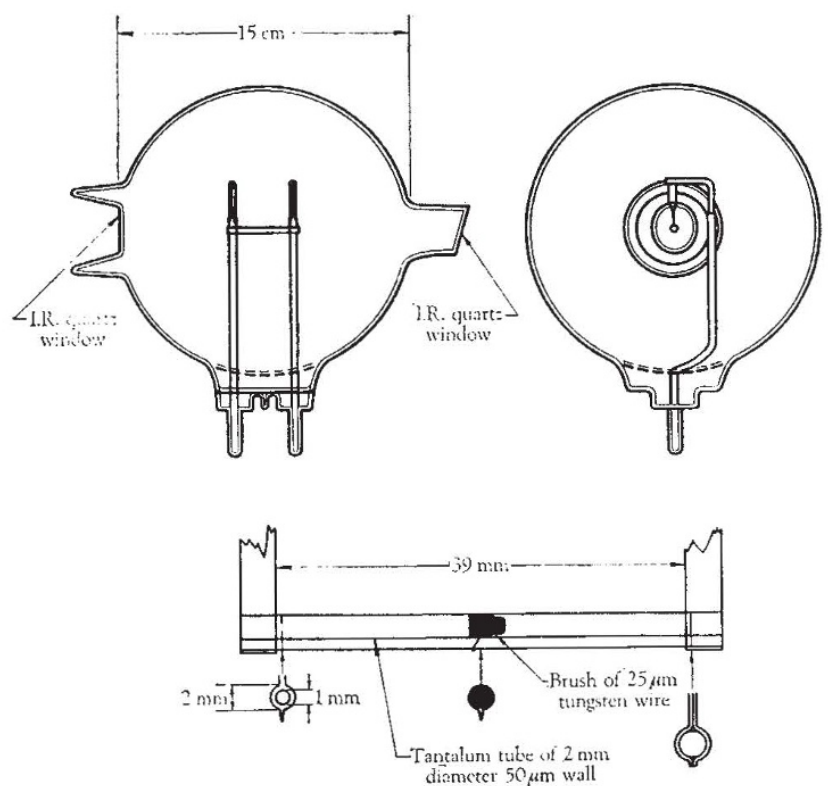

Fig. 1. Details of black body lamp mate to that from a full radiator. Near the other end of the tube is placed a diaphragm completely closing the tube.

This construction has been tried with satisfactory results in a vacuum lamp operating up to $1,550^{\circ} \mathrm{C}$ $(2.7 \mathrm{~V}, 25 \mathrm{amp})$ and in a gas-fillod lamp up to $2.500^{\circ} \mathrm{C}$ $(9.0 \mathrm{~V}, 72 \mathrm{amp})$. It is proposed to improve the efficiency of the gas-filled lamp by the addition of a concentric cylindrical radiation shield. Experiments with the vacuum lamp have shown that the fundamental requirement that a disk of light uniform in luminance should be provided has been fulfilled within the limit of 0.1 per cent variation. It is, of course, more difficult to establish the emissivity achieved. That the approximation to a full radiator is quite close has been established by measuring the temperature of the disk and the outer surface of the tube at the centre with a disappearing filament optical pyrometer operating at a wave-longth of $0.66 \mu \mathrm{m}$. The emissivity of tantalum at this wave-length, calculated from these luminance temperatures, is in agreement with the accepted value.

The advantages which accrue then from the use of a full radiator as a standard source are: (1) The true temperature, the luminance temperature and the colour temperature are the same. (2) Changes in the surfaco condition of the refractory body would not affect directly the calibration of the lamp. (3) The disk of light to be used is well defined and is uniform in luminance. (4) Variations in luminance and degree of polarization with angle of emission are eliminated. (5) A higher maximum luminance temperature is achieved. If the limiting luminance temperature in the red of the strip lamp were $2,650^{\circ} \mathrm{K}$, the total radiator lamp would give $3,000^{\circ} \mathrm{K}$ for the same true temperature of the refractory body.

\section{R. BARBER}

T. J. QUINN

Standards Division,

National Physical Laboratory, Teddington, Middlesex.

E. B. POWER

W. J. Holloway

The General Flectric Co. Ltd.,

Hirst Research Centre,

Wembloy,

Middlesex.

1 Barber, C, R., J. Sci. Instr., 23, 238 (1946).

${ }^{2}$ Jones, T. P., J. Sci. Instr., 40, 101 (1963).

${ }^{3}$ Brouwer, G. P., Philips Res. Rep., 18, 361 (1963).

\section{Charge Transfer associated with Temperature Gradients in Ionic Solutions}

Potential differences were produced across columns of sodium chloride or potassium chloride solution when temperature gradients were applied along them. The contribution made by this mechanism to the potentials recorded across cell membranes is unlikely to be large.

A solution of sodium chloride or potassium chloride was contained within a hollow vertical ebonite cylinder of height $12 \mathrm{~cm}$ and internal diameter $2.5 \mathrm{~cm}$. The base of the cylinder was sealed by means of an earthed brass plug which made good thermal contact with the solution but was separated from it electrically by means of a thin sheet of insulation. The solution could be heated by means of an carthed electrical heater located at the top of the liquid column. In this way, temperature differences of up to $22^{\circ} \mathrm{C}$ could be applied between two brass electrodes $2 \mathrm{~cm}$ apart which made contact with the solution through the walls of the ebonite cylinder about half-way along its length. The upper electrode was earthed and the lower one was connected to a vibrating reed electrometer in series with a pen-recorder which recorded the potentials devel- 